\title{
Extração com Fluido Supercrítico
}

\author{
Glaucia M. F. Pinto \\ Pontifícia Universidade Católica de Campinas, Faculdade de Química \\ Jefferson F. Pinto \\ Protimu Ltda
}

Isabel C. S. F. Jardim *

icsfj@iqm.unicamp.br

Universidade Estadual de Campinas, Instituto de Química

Informações do Artigo

Histórico do Artigo

Criado em Abril de 2006

\section{Palavras-Chaves}

Extração

Fluido supercrítico

Química Analítica

Fluido extrator

Cromatografia
Resumo

Neste trabalho apresentou-se uma discussão das características da extração com fluido supercrítico, suas condições de operação, uma comparação com outras técnicas de extração e aplicações analíticas da técnica.

O trabalho mostra que um fluido supercrítico pode ser obtido com diferentes substâncias se as mesmas se encontrarem acima do ponto crítico, da temperatura crítica e pressão crítica, o que pode ser visualizado em um diagrama de fases. Dentre os fluidos supercríticos mais utilizados destaca-se o dióxido de carbono devido a seus baixos parâmetros críticos, não toxicidade, não inflamabilidade, não reatividade, possibilidade de obtenção com alto grau de pureza, grande acessibilidade, baixo custo e ser gasoso em temperatura ambiente, sendo que este ainda pode ser modificado pela adição de solventes orgânicos. A operação da extração com fluido supercrítico permite o acoplamento on-line e a recuperação do solvente utilizado. Os parâmetros que governam a SFE são discutidos, principalmente pressão, temperatura, natureza da matriz e polaridade do fluido extrator. Alguns aspectos de comparação mostram que a extração com fluido supercrítico é uma técnica atrativa para ser aplicada no preparo de amostras sólidas, pois apresenta vantagens em relação às outras alternativas de técnicas de preparo de amostra (soxhlet, ultra-som, extração por solvente acelerado, entre outras), devido as características de rapidez; baixo custo por extração; reduzido consumo de solventes orgânicos; baixa manipulação; boa precisão e exatidão; versatilidade; boa recuperação e facilidade de automação.

O trabalho ainda apresenta algumas aplicações da SFE, que hoje são muito numerosas e variadas, incluindo amostras ambientais (solo, água, ar, sedimentos, suspensões e tecidos animais), alimentos (frutas, vegetais, cereais, tecidos animais...), produtos naturais (óleos essências, aromas...), fármacos (drogas de abuso, hormônios...) e polímeros. 


\section{Objetivo}

Descrever a técnica de preparo de amostra de extração com fluido supercrítico, seus parâmetros e esquema de operação básico, correlacionando com outras técnicas de preparo de amostras e apresentando alguns exemplos de aplicações típicas em química analítica.

\section{Introdução}

A extração com fluido supercrítico (SFE - "Supercritical Fluid Extraction") é uma técnica de extração utilizada principalmente quando se deseja retirar substâncias de interesse (analitos) de matrizes sólidas. Ela emprega um fluido em condições supercríticas, que apresenta propriedades intermediárias entre um gás e um líquido.

O crescimento desta técnica está relacionado com a preocupação da comunidade científica com a saúde e o bem estar do ser humano, gerando a necessidade de analisar matrizes cada vez mais complexas (como águas naturais, solos, sedimentos e ar, além de amostras de alimentos, plantas, frutas, plásticos, etc.), com baixos níveis de concentração (traços e sub-traços).

\section{O fluido supercrítico}

O primeiro relato da observação de uma fase supercrítica ocorreu em 1822, feito pelo Barão Cagniard de la Tour. Ele notou, visualmente, que a separação de fases entre um gás e um líquido desaparecia quando certas substâncias eram aquecidas em recipientes fechados [1].

Um fluido supercrítico (SF-"Supercritical Fluid") é definido como sendo formado acima do ponto crítico, da temperatura crítica $(\mathrm{Tc})$ e pressão crítica $(\mathrm{Pc})$, o que pode ser visualizado em um diagrama de fases, apresentado na Figura 1.

Quando somente um valor crítico é atingido (temperatura ou pressão) o fluido é considerado em estado subcrítico [5].

Acimadopontocrítico, algumas propriedadesdasubstância, como densidade e viscosidade, são intermediárias entre um gás e um líquido. O fluido adquire uma densidade similar

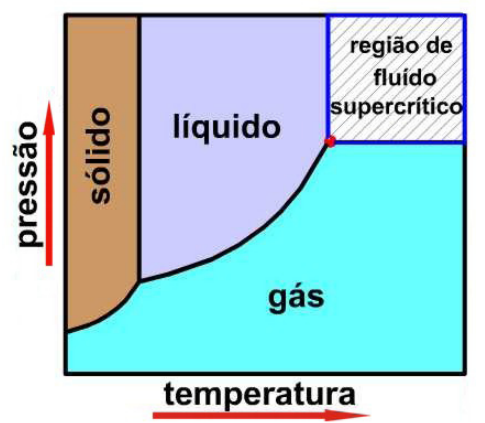

Figura 1. Diagrama de fases mostrando a região do fluido supercrítico para o dióxido de carbono [1,2-4].

à de um líquido (e portanto um poder de solvatação) e simultaneamente uma compressibilidade parecida com a de um gás. O grande poder de solvatação ocasiona uma alta permeação do fluido na amostra, aumentando a probabilidade de uma extração completa $[2,6]$.

$\mathrm{Na}$ Tabela 1 apresentam-se as propriedades físicas do $\mathrm{SF}$ e observa-se, comparando com as propriedades de líquidos e gases, que o SF apresenta alta densidade, baixa viscosidade e difusibilidade superior à da fase líquida (o que explica a grande e atrativa taxa de transferência de massas do SF) $[1,2,4]$.

Tabela 1. Ordens de magnitude de parâmetros físicos para gases, fluidos supercríticos e líquidos (adaptada da Ref. 1).

\begin{tabular}{|l|l|l|l|}
\hline Objeto & $\begin{array}{l}\text { Densidade / } \\
\mathbf{g} \mathbf{~ m L}^{-1}\end{array}$ & $\begin{array}{l}\text { Viscosidade } \\
\text { dinâmica/ } \\
\mathbf{g ~ c m}^{-1} \mathbf{s}^{-1}\end{array}$ & $\begin{array}{l}\text { Coeficiente } \\
\mathbf{d e ~ d i f u s a ̃ o ~ / ~} \\
\mathbf{c m}^{2} / \mathbf{s}^{-1}\end{array}$ \\
\hline $\begin{array}{l}\text { Gás } \\
\text { (ambiente) }\end{array}$ & $0,0006-0,002$ & $0,0001-0,003$ & $0,1-0,4$ \\
\hline $\begin{array}{l}\text { Fluido } \\
\text { supercrítico } \\
\text { (T, } \mathrm{P} \text { ) }\end{array}$ & $0,2-0,5$ & $0,0001-0,0003$ & 0,0007 \\
\hline $\begin{array}{l}\text { Líquido } \\
\text { (ambiente) }\end{array}$ & $0,6-1,6$ & $0,002-0,03$ & $\begin{array}{l}0,000002 \\
-0,00002\end{array}$ \\
\hline
\end{tabular}

Uma das propriedades mais importantes de um fluido supercrítico, que está relacionada à sua alta densidade $(0,2$ a $\left.0,5 \mathrm{~g} \mathrm{~mL}^{-1}\right)$, é a sua capacidade de dissolver moléculas não-voláteis de alta massa molar. Por exemplo, o dióxido de carbono supercrítico dissolve n-alcanos com 5 a 30 átomos de carbono [2]. Além disso, a alta difusibilidade do fluido supercrítico garante extrações rápidas.

Outra importante característica do SF é que sua densidade pode ser precisamente ajustada, variando os valores de temperatura e pressão (situação compreendida pela observação do gráfico da Figura 2), enquanto a densidade de um líquido só é alterada pela adição de outros solventes ou com uma grande elevação da temperatura. Esta característica de densidade variável é responsável 
pela grande seletividade dos SF, o que representa uma vantagem, principalmente para matrizes complexas de origem ambiental $[1,3,4]$.

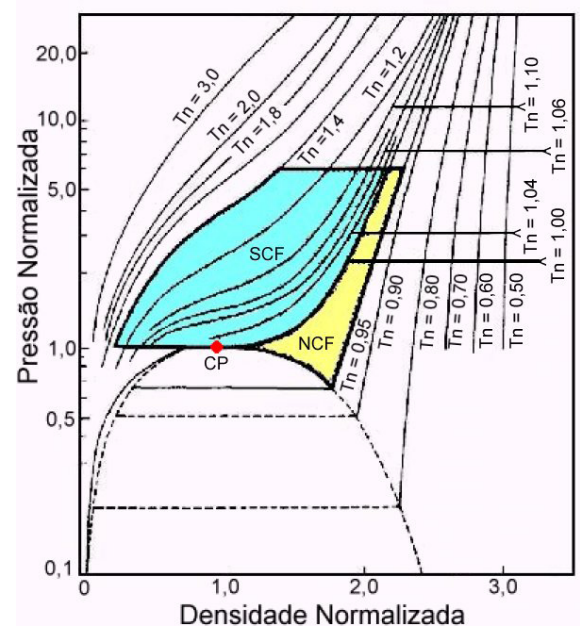

Figura 2. Gráfico mostrando a correlação entre densidade, pressão e temperatura, $\mathrm{SCF}=$ região do fluido supercrítico, $\mathrm{NCF}=$ região próxima ao líquido crítico $=$ região subcrítica, $\mathrm{CP}=$ ponto crítico (adaptada da Ref. 1).

\section{Os fluidos supercríticos mais utili-} zados

Sem dúvida, o fluido supercrítico mais utilizado é o dióxido de carbono devido a seus baixos parâmetros críticos (Tabela 2), não toxicidade, não inflamabilidade, não reatividade, possibilidade de obtenção com alto grau de pureza, grande acessibilidade, baixo custo e ser gasoso em temperatura ambiente (o que facilita a separação do analito extraído) $[1,3,4,7]$.

Tabela 2. Temperatura, pressão e densidade (dc) críticas para alguns solventes [1].

\begin{tabular}{|l|l|l|l|}
\hline Solvente & $\mathbf{T}_{\text {critica }} /{ }^{\circ} \mathbf{C}$ & $\mathbf{P}_{\text {critica }} / \mathbf{M P a}$ & $\mathbf{d}_{\text {critica }} / \mathbf{g ~ m L}^{-1}$ \\
\hline Xenônio & 16,6 & 5,76 & 1,10 \\
\hline Trifluorometano & 25,9 & 4,69 & 0,52 \\
\hline Clorotrifluorometano & 29,0 & 3,87 & 0,58 \\
\hline Dióxido de Carbono & 31,0 & 7,29 & 0,47 \\
\hline Óxido Nitroso & 36,5 & 7,17 & 0,45 \\
\hline $\begin{array}{l}\text { Hexafluoreto de } \\
\text { Enxofre }\end{array}$ & 45,5 & 3,71 & 0,74 \\
\hline Clorodifluorometano & 96,4 & 4,85 & ---- \\
\hline Propano & 96,8 & 4,24 & 0,22 \\
\hline Amônia & 132,4 & 11,13 & 0,24 \\
\hline Triclorofluorometano & 198,0 & 4,35 & ---- \\
\hline Água & 374,0 & 21,77 & 0,30 \\
\hline
\end{tabular}

Existem SF que podem ser considerados opções em substituição ao dióxido de carbono, mas todos apresentam desvantagens que inibem o seu uso: os clorofluorcarbonos são "inimigos" ambientais, pois destroem a camada de ozônio e causam o efeito estufa, o óxido nitroso pode ser explosivo na presença de matéria orgânica e tende a se decompor espontaneamente, o xenônio apresenta custo muito elevado, a amônia tem alta reatividade, entre outros $[1,5]$.

O dióxido de carbono só não pode ser considerado um SF perfeito porque, devido a sua alta densidade, apresenta uma capacidade limitada de dissolver moléculas polares. Esta desvantagem geralmente é contornada pela adição de modificadores, também chamados de co-solventes ou "entrainers". Os modificadores podem ser solventes orgânicos, reagentes derivatizantes ou reagentes de pariônico. Eles são adicionados continuamente no fluxo de SF (acarretando na necessidade do uso de uma segunda bomba) ou diretamente na amostra. Neste caso, as vantagens são o favorecimento da dessorção do analito e a diminuição do volume de solvente, mas a desvantagem é a necessidade de um período estático adicional $[1,5,8]$.

A função dos modificadores é facilitar a solubilidade e a dessorção do analito do sítio ativo da matriz. Porém, os co-solventes devem ser adicionados em baixa concentração (a concentração mais usada é de no máximo $10 \% \mathrm{v} / \mathrm{v}$ ), pois uma adição excessiva pode ocasionar efeitos indesejáveis, uma vez que os parâmetros críticos do SF são alterados para condições mais drásticas, podendo levar a condições subcríticas, na qual a seletividade é reduzida, pode-se necessitar de uma etapa de "clean-up" prévia à análise e a eficiência da coleta do soluto extraído corre o risco de ser prejudicada [1]. A incorporação do modificador altera muito o poder de solvatação do SF e o efeito na transferência de massa também é modificado, especialmente se o modificador interagir com o soluto [1]. Os modificadores mais utilizados são os solventes orgânicos e dentre eles o mais empregado é o metanol, mas a acetona, o clorofórmio, o diclorometano e a acetonitrila também têm sido bastante usados [8].

A água, apesar de muitas vezes ser considerada prejudicial no mecanismo de extração, têm sido utilizada em alguns trabalhos como modificadora $[9,10]$, pois verificou-se que ela ocasiona um inchaço da matriz, o que favorece a extração em certos casos. O uso de água supercrítica apresenta desvantagens, pois as condições de temperatura e pressão necessárias são elevadas e nestas condições, se uma desgaseificação muito eficiente não for realizada, a água torna-se muito corrosiva para o sistema de aço inoxidável. 
Uma alternativa recente e interessante ao uso de dióxido de carbono modificado, empregada na extração de compostos polares, é o uso de água subcrítica, isto é, água aquecida sob condições moderadas e constantes de pressão. Nestas condições, a pressão apresenta menor efeito, pois as mudanças de densidade são menores. À temperatura elevada $\left(200^{\circ} \mathrm{C}\right)$ e pressão de aproximadamente $5 \mathrm{MPa}$, a polaridade da água torna-se similar à do metanol ou da acetonitrila e a tensão superficial e a viscosidade também são reduzidas para valores próximos as do metanol e da acetonitrila [11,12].

Field et al. [13] utilizaram a SFE com dióxido de carbono e extração com água subcrítica, seqüencialmente, para determinar Dacthal e seus metabólitos ácidos (mono e dicarboxílicos) em solo. A recuperação dos metabólitos ácidos utilizando SFE com dióxido de carbono com metanol e acetonitrila foi menor que 50\%, mas com água subcrítica foi maior que $90 \%$.

Crescenzi et al. [14] analisaram multirresíduos de herbicidas em solo utilizando água subcrítica, obtendo resultados superiores aos obtidos com extração Soxhlet e a extração por ultrassonificação (USE - "Ultra Soniffication Extraction").

\section{Operação da SFE}

O processo de SFE pode ser dividido em quatro estágios principais: dessorção do analito da matriz, solubilização do analito pelo fluido supercrítico, arraste do analito para fora da célula de extração e coleta do analito extraído $[7,15]$. A Figura 3 mostra um esquema de um sistema básico de SFE.

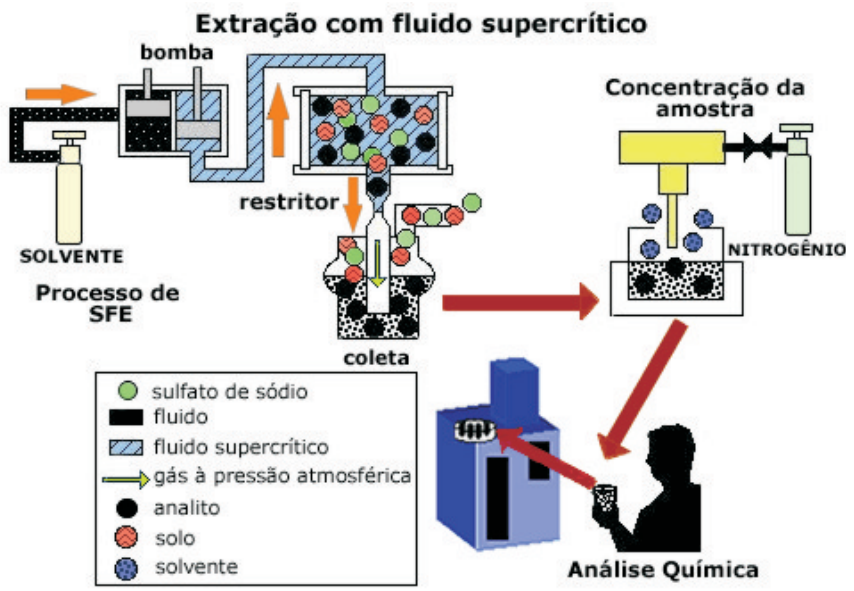

Figura 3. Esquema de operação de uma extração com fluido supercrítico, incluindo a etapa de concentração (opcional) e a etapa de análise química [16].
A operação de extração inicia-se com o bombeamento do solvente para a célula extratora que contem a amostra. O gás é então pressurizado e aquecido até chegar às condições desejadas. Na célula extratora, ocorre o contato entre a amostra e o fluido supercrítico, que pode ser de maneira dinâmica, na qual o SF é continuamente passado através da matriz ou estática, na qual se emprega uma quantidade fixa de SF que permanece um período de tempo em contato com a matriz, acontecendo a extração. Após esta etapa, o extrato obtido é levado até um restritor (fixo ou variável), no qual há um controle de temperatura e pressão. $\mathrm{O}$ extrato é separado do fluido, que retorna ao seu estado físico original (devido à despressurização), é recolhido em um sistema de coleta utilizando geralmente um solvente, um sistema criogênico, uma retenção em fase sólida adequada ou ainda acoplamento "on-line" com um sistema de análise ou detecção. O solvente extrator normalmente é recolhido e reciclado.

\section{Parâmetros da SFE}

Os parâmetros que governam a SFE são principalmente: pressão, temperatura, natureza da matriz e polaridade do fluido extrator $[5,7]$.

\section{Pressão}

Existe uma pressão, conhecida como "threshold pressure", na qual o soluto começa a se solubilizar no fluido supercrítico. Esta zona de solubilidade aumenta muito rapidamente com a pressão, que corresponde ao aumento rápido na densidade do fluido, até atingir um valor máximo. Após o valor máximo ocorre ligeira queda de solubilidade com o aumento da pressão, o que pode ser explicado pelas forças de repulsão entre as moléculas do soluto dissolvidas no fluido supercrítico.

O controle da pressão permite realizar uma extração seletiva. A título de exemplo, pode-se realizar a extração seletiva de alcanos a uma temperatura de $45^{\circ} \mathrm{C}$ e uma pressão de 7,5 $\mathrm{MPa}$, em relação aos hidrocarbonetos poliaromáticos $(\mathrm{PAH})$, extraídos a uma temperatura de $45^{\circ} \mathrm{C}$ e uma pressão de $30 \mathrm{MPa}[5,7,17]$.

\section{Temperatura}

Um aumento da temperatura, à pressão constante, ocasiona 
uma diminuição na densidade do fluido supercrítico e portanto no seu poder de solvatação. Logo, os compostos não voláteis terão sua solubilidade diminuída nestas condições e em conseqüência, o rendimento da extração será diminuído. O comportamento dos compostos voláteis é mais complexo, pois a solubilidade deles no fluido supercrítico depende do poder de solvatação do fluido e das tensões do vapor [7].

Nas matrizes naturais, nas quais a grande maioria dos solutos encontra-se fixo nos sítios ativos da matriz, uma elevação da temperatura resulta em um aumento do rendimento de extração, independente da volatilidade do soluto. Isto ocorre pois há um aumento na energia térmica, que facilita a dessorção dos solutos fixos nos sítios ativos da matriz $[7,17]$.

O ponto de fusão dos solutos de interesse também é um fator importante, uma vez que muitos solutos dissolvemse mais facilmente no fluido supercrítico se estiverem no estado líquido [17].

Deve-se lembrar que a elevação da temperatura é prejudicial no caso de moléculas orgânicas termolábeis.

\section{Natureza da matriz}

O rendimento da extração depende fortemente das características da matriz, principalmente natureza dos sítios ativos, superfície específica, porosidade, polaridade e umidade [7].

Em análises ambientais utilizando SFE, a matriz mais comum estudada é o solo, o qual por si já constitui uma ciência específica [17]. Para aumentar a superfície de contato entre a matriz e o SF, intensificando a transferência de soluto para o SF, as partículas do solo devem ser as menores possíveis. Amostras de solo com alto teor de enxofre elementar devem sofrer a adição de cobre particulado, pois a formação de sulfeto de cobre inibe possíveis interferências, uma vez que o enxofre pode ser extraído durante a SFE e causar obstruções no restritor [9].

A presença de água na amostra é um assunto delicado. Como regra geral, quantidades ao redor de $5 \%$ podem favorecer o rendimento da extração devido ao efeito de inchaço da amostra, facilitando a difusão do fluido supercrítico e aumentando a polaridade do fluido, funcionando como um modificador. Um excesso de água, por outro lado, vai ocasionar uma diminuição no rendimento da extração, principalmente devido à formação de "plugging" no restritor, ocasionado pela baixa solubilidade da água no fluido supercrítico. Devido a isso, se o fluido supercrítico utilizado na extração for o dióxido de carbono provavelmente ocorrerá a formação de pequenas partículas de gelo $[5,8]$.

Para evitar a presença indesejável da água, um procedimento comumente adotado é a adição de agentes secantes, como o "Hydromatrix" (uma terra de diatomácea peletizada), o sulfato de magnésio, o sulfato de sódio, o celite ou a celulose CF-1. As desvantagens dos sulfatos de sódio e magnésio são as baixas capacidades relativas de retenção de água e, além disso, o sulfato de magnésio aquece quando hidrata. Os sulfatos podem ainda obstruir o restritor devido a suas partículas pequenas e formar aglomerados quando misturados com a água. De fato, o "Hydromatrix" parece ser o agente secante mais eficiente, apresentando, como principal vantagem, o fato de reter até duas vezes sua massa em água. Um ponto a ser considerado, é que os agentes secantes "Hydromatrix", celite e celulose CF-1 mostraram retenção parcial de alguns pesticidas [5].

\section{Polaridade do fluido extrator}

Como previamente mencionado, a presença de um modificador altera a polaridade do SF. Os mecanismos de interação do modificador não são bem explicados, mas existem quatro modos de ação propostos [5]:

- ocorre um aumento da solubilidade dos solutos devido à mistura do $\mathrm{SF}$ com o solvente polar;

- ocorre uma troca dos solutos fixos nos sítios ativos da superfície da matriz pelo solvente modificador;

- há uma fixação do solvente modificador na superfície da matriz evitando que ocorra uma readsorção dos solutos;

- ocorre uma solvatação adicional da matriz (inchaço) facilitando a penetração do SF.

Provavelmente, em amostras de solo contaminadas naturalmente, matrizes vegetais e biológicas, os três primeiros modos de ação ocorram simultaneamente [7].

\section{SFE e Outras Técnicas de Extração}

Nasúltimas décadas, a preocupação comodesenvolvimento de técnicas analíticas mais modernas foi bastante intensa, fazendo com que hoje a etapa de análise apresente alto 
grau de tecnologia, rapidez, precisão e exatidão.

O mesmo não ocorreu com a etapa de preparo da amostra. Assim, mais recentemente, percebeu-se que esta etapa representa uma parcela excessiva do tempo (61\%) [1] e do custo total da análise, e também é a maior responsável pelo erro associado ao resultado final.

Esta realidade ocasionou uma grande preocupação com o desenvolvimento das técnicas de extração de analitos de matrizes complexas, pois sem elas a determinação não é possível. Buscando principalmente, as seguintes características:

- Rapidez;

- Baixo custo por extração;

- Reduzido consumo de solventes orgânicos;

- Baixa manipulação;

- Boa precisão e exatidão;

- Versatilidade;

- Boa recuperação;

- Facilidade de automação.

Têm-se desenvolvido técnicas de extração alternativas para as tradicionalmente utilizadas (que não possuem tais características): extração líquido-líquido (LLE - "LiquidLiquid Extraction”), utilizada para amostras líquidas e extração por solvente (Soxhlet), utilizada para amostras sólidas.

A extração em fase sólida (SPE - "Solid Phase Extraction") e a microextração em fase sólida (SPME - "Micro Solid Phase Extraction"), têm substituído, com sucesso, a maioria das aplicações da LLE. Como alternativa à extração Soxhlet surgiram a extração assistida por microondas (MAE - "Microwave Assisted Extraction"), a extração com fluido supercrítico (SFE), a extração por ultrassonificação (USE - "Ultra Soniffication Extraction") e a extração por solvente acelerado (ASE - "Accelerate Solvent Extraction"), sendo que a SFE e a ASE são as que têm se mostrado mais atrativas para substituir a extração Soxhlet.

MAE e USE são técnicas baseadas na utilização de uma quantidade reduzida de solvente, escolhido de acordo com a natureza do analito de interesse, no qual o processo de extração é acelerado pelo uso de um tipo de energia, microondas e ultra-som, respectivamente. Os resultados de extração obtidos são geralmente equivalentes aos da extração Soxhlet, mas o tempo gasto não ultrapassa 30 min, na maioria dos casos [18].

A ASE é a técnica mais recente e utiliza temperatura elevada $\left(50-200{ }^{\circ} \mathrm{C}\right)$ e, conseqüentemente, pressão alta (3,5-21 MPa), para manter o solvente no estado líquido. Esta técnica permite obter extrações quantitativas em aproximadamente $15 \mathrm{~min}$. [18].

O inconveniente principal da USE, MAE e ASE é que estas técnicas, inevitavelmente, co-extraem compostos indesejáveis da matriz, resultando na necessidade de incluir uma etapa de "clean-up" [18].

Assim, a SFE apresenta uma vantagem importante sobre as demais técnicas citadas, pois além de ser rápida e utilizar baixo volume de solventes, possui uma alta seletividade, excluindo a necessidade de eliminação de interferentes, previamente à análise [18].

O tempo de preparo de uma amostra utilizando SFE pode variar entre $15 \mathrm{~min}$ a $2 \mathrm{~h}$, enquanto que utilizando extração Soxhlet este tempo oscila entre 16 e 30 h. O volume de solvente orgânico gasto em uma SFE é, em média, de $15 \mathrm{~mL}$ (se o trapeamento for realizado com solvente), já utilizando a extração Soxhlet o volume médio de solvente gasto é de $150 \mathrm{~mL}$. Calcula-se que o custo de extração por amostra, utilizando SFE seja ao redor de US \$ 5.50 versus US\$22.00 para o método convencional [16].

Estes e outros fatores têm despertado a atenção dos pesquisadores para a SFE e muito se tem investido no desenvolvimento e investigação de novas e variadas aplicações para esta técnica de extração, principalmente na área ambiental, devido à complexidade das matrizes envolvidas (que requerem um método eficiente de extração) e pelo fato de que, nos dias atuais, o interesse global nesta área supera qualquer outra.

Outros fatores que impulsionaram o desenvolvimento e o aumento da utilização da SFE em escala analítica foram: a) o investimento e a disponibilização de equipamentos comerciais, sendo atualmente sete os fabricantes de equipamentos, com a ISCO liderando o mercado $[11,12]$ e b) o surgimento de um método oficial da Agência de Proteção Ambiental Norte-Americana (EPA "Environmental Protection Agency"), em 1992 (Método 3560 para determinação de hidrocarbonetos de petróleo em solos). Hoje existem mais dois métodos oficiais da EPA que utilizam SFE: Método 3561, para análise de hidrocarbonetos aromáticos polinucleares (PAH) e método 3562, para análise de bifenóis polinucleares (PCB) e pesticidas organoclorados $(\mathrm{OCP}) \mathrm{em}$ solos, sedimentos, aerossóis e outros materiais sólidos.

Dentre as principais desvantagens da SFE devem-se citar: 
$[12,19]$.

- Alto custo instrumental (de US\$10 a 80 mil);

- Grande número de parâmetros para otimizar e controlar;

- Laborioso desenvolvimento de método;

- Condições de extração fortemente dependentes da matriz.

Um dos fatores importantes para decidir se as vantagens da SFE compensam as desvantagens é o número de análises que o laboratório interessado na técnica realiza.

\section{Aplicações da SFE em Química Analítica}

Apesar das aplicações da SFE na área analítica serem relativamente recentes, meados da década de 80 , esta técnica de extração tem sido utilizada há muito tempo em aplicações industriais. Os primeiros a utilizarem o poder de solvatação do SF foram Hannay e Hogarth em 1879 [1], estudando a solubilidade do cloreto de cobalto (II), cloreto de ferro (II), brometo de potássio e iodeto de potássio em etanol supercrítico [1]. Após isto, os estudos com SF foram intensificados surgindo várias patentes para extração de diversos produtos naturais, como extração de cafeína do café, extração da nicotina do tabaco, obtenção de aromatizantes de diversas especiarias, além de aplicações que incluem extração de óleos vegetais, preparação de alimentos dietéticos (eliminação de gorduras), purificação de compostos e etc. Sem dúvida, a aplicação industrial de maior destaque é a obtenção do café descafeinado, que antes da utilização da SFE era obtido por extração com solventes orgânicos tóxicos.

Hoje, as aplicações da SFE são muito numerosas e variadas, incluindo amostras ambientais (solo, água, ar, sedimentos, suspensões e tecidos animais), alimentos (frutas, vegetais, cereais, tecidos animais...), produtos naturais (óleos essências, aromas...), fármacos (drogas de abuso, hormônios...) e polímeros.

Muitas pesquisas tentam mostrar as potencialidades do uso de SFE. Tais pesquisas deixam claro que, apesar da potencialidade, isto é, da SFE poder ser aplicada à uma ampla variedade de matrizes, para determinação de diversos analitos, muitas vezes as condições específicas que devem ser usadas para tornar a extração possível ou eficiente, não compensam as vantagens apresentadas, e portanto, apesar de potencial, o uso da SFE deixa de ser viável.

Algumas aplicações mais recentes e relevantes foram selecionadas, com grande destaque para as aplicações na área ambiental:

\section{Amostras ambientais}

a) Matrizes sólidas (solo e sedimentos)

Solo e sedimentos apresentam grande interesse ambiental, pois sabe-se que eles estão interligados com os demais compartimentos do ecossistema, existindo processos de transporte de contaminantes dos solos (ou sedimentos) para a água e o ar, influenciando, portanto, na contaminação do meio ambiente como um todo.

Sem dúvida, o solo é a matriz ambiental na qual o uso da SFE apresenta maior potencialidade e viabilidade. Isto porque, fora alguns cuidados prévios com a amostra (controle da umidade, tamanho de partículas e adição de cobre para eliminação de enxofre) nenhuma condição especial de análise é necessária. A amostra sólida é adicionada diretamente na célula extratora. Além disso, os conceitos envolvidos são relativamente simples e bem estabelecidos.

$\mathrm{Na}$ maioria dos casos, o dióxido de carbono é um fluido supercrítico bastante adequado, sendo que a necessidade de adição de um modificador depende do analito.

Os analitos mais extraídos em amostras deste tipo são: $\mathrm{PAH}, \mathrm{PCB}$ e pesticidas.

Morselli et al. [20] determinaram hidrocarbonetos de petróleo em solos utilizando SFE. Foram utilizadas amostras de solo fortificadas para as determinações. As extrações foram realizadas em um equipamento Hewlett-Packard modelo 7650T, utilizando dióxido de carbono e extração dinâmica e estática. Foram adicionados 5 ou $10 \%(\mathrm{v} / \mathrm{v})$ de acetona, como modificador, diretamente na célula de extração. As extrações foram realizadas a uma temperatura de 80 ${ }^{\circ} \mathrm{C}$ e uma pressão de 22,7 $\mathrm{MPa}$, sendo a coleta feita em fase estacionária octadecilsiloxano (C18).

A sorção dos hidrocarbonetos foi avaliada utilizando a equação de Freundlich e verificou-se que ela depende fortemente do conteúdo de matéria orgânica dos solos. Avaliou-se que as recuperações do analito 
dependem da soma do equilíbrio entre as extrações dinâmicas e estáticas. Verificou-se que a presença de $5 \%$ (v/v) de acetona como modificador foi a condição que forneceu os melhores resultados.

Berset e Holzer [10] desenvolveram um método para extração, utilizando SFE, e quantificação, utilizando cromatografia gasosa de alta resolução acoplada à espectrometria de massas, de alguns dos principais contaminantes ambientais: os $\mathrm{PAH}$, os $\mathrm{PCB}$ e os OCP.

A matriz analisada era constituída por uma suspensão de esgoto doméstico, industrial e esgoto obtido após o escoamento superficial de água. Foi adicionado cobre às amostras secas, para um tratamento prévio, e as SFE foram realizadas utilizando um equipamento Hewlett-Packard 7680T, sendo as condições de extração diferenciadas para cada tipo de contaminante.

As extrações de PAH foram realizadas em três etapas com extrações dinâmicas e estáticas. A primeira utilizou dióxido de carbono, temperatura de $80{ }^{\circ} \mathrm{C}$, pressão de 12,1 MPa e coleta em fase sólida (C18). $\mathrm{Na}$ segunda o SF foi dióxido de carbono com $1 \%(\mathrm{v} / \mathrm{v})$ de metanol e $4 \%(\mathrm{v} / \mathrm{v})$ de diclorometano, temperatura de $120^{\circ} \mathrm{C}$, pressão de $33,5 \mathrm{MPa}$. A terceira etapa também foi realizada com dióxido de carbono puro como SF nas mesmas condições de temperatura e pressão da segunda etapa.

A primeira etapa de extração dos $\mathrm{PAH}$ visou a extração dos PAH mais voláteis, a segunda etapa extraiu os PAH menos voláteis e a terceira etapa foi usada para purgar o sistema e prepará-lo para a próxima extração. Antes do experimento, houve a adição de $20 \%(\mathrm{v} / \mathrm{m})$ de água para ocupar os sítios polares da matriz e facilitar a extração.

As extrações de PCB foram realizadas empregando extração dinâmica e estática, com dióxido de carbono puro, temperatura de $80^{\circ} \mathrm{C}$ e pressão de $30,5 \mathrm{MPa}$. A coleta do extrato foi feita em Florisil.

Para os OCP, as extrações foram realizadas dinâmica e estaticamente, utilizando dióxido de carbono puro como SF, temperatura de $50^{\circ} \mathrm{C}$, pressão de $29,9 \mathrm{MPa}$ e coleta em C18.

Os extratos sofreram uma etapa de "clean-up" utilizando colunas de sílica gel (PAH e PCB) e coluna de terra de diatomáceas (OCP). As recuperações obtidas foram boas, com valores muito próximos a $100 \%$ na grande maioria dos casos.

Os níveis de concentração encontrados foram, em média, de $6,9 \mathrm{mg} / \mathrm{kg}$ (massa seca) para a soma de 16 PAH constantes na lista da EPA; 0,1 mg/ $\mathrm{kg}$ (massa seca) para a soma de sete PCB estudados, e 0,002$0,072 \mathrm{mg} / \mathrm{kg}$ (massa seca) para os OCP determinados no esgoto. Só foi encontrada correlação entre tipo de esgoto e grau de contaminação para os $\mathrm{PAH}$.

Rissato et al. [21] desenvolveram um método multiressíduo para determinação de pesticidas organoclorados, organonitrogenados, organofosforados e pireteróides em solo usando a SFE e compararam o rendimento obtido com o de extração sólido-líquido convencional. A determinação dos pesticidas foi feita por cromatografia gasosa com detector de captura de elétrons (GC-ECD) e por cromatografia gasosa acoplada à espectrometria de massas (GC-MS), precedida de uma etapa de "cleanup" utilização cartuchos C18. Alguns parâmetros experimentais relevantes para a eficiência de extração foram estudados, pressão de $40 \mathrm{MPa}$, temperatura de extração de $60{ }^{\circ} \mathrm{C}$ e tempo de $20 \mathrm{~min}$. Como a sorção de pesticidas pode ser afetada pelo tempo de residência no solo, amostras de solo fortificadas foram extraídas após períodos diferentes de repouso (1, 20 e 40 dias). Uma amostra de solo real, coletada em um campo agrícola em Bauru (SP-Brasil), também foi analisada empregando as condições experimentais já otimizadas para SFE e extração sólido-líquido. Os resultados obtidos mostraram que a SFE pode ser utilizada para extrair uma grande quantidade de pesticidas de diferentes classes de amostras de solo com menor tempo de extração e uso reduzido de solventes, obtendo-se valores de recuperação acima de $80 \%$.

b) Matrizes líquidas (água)

A água é o recurso natural de maior importância para os seres vivos, uma vez que um homem (por exemplo) pode passar vários dias sem comer, mas não pode passar 2 dias sem beber água. Além disso, o homem tem cada vez mais consciência de que a água é um recurso finito e então, vem crescendo a preocupação com relação às contaminações deste recurso.

Esta matriz é talvez a que apresente maiores dificuldades nas tentativas de utilização da SFE.

O parâmetro decisivo na extração de amostras de 
água (ou líquidas genericamente) é o coeficiente de distribuição do analito entre o SF e a fase líquida. Do ponto de vista do transporte do analito, a extração dinâmica é preferida em relação à estática devido a problemas de possíveis precipitações do analito durante o processo de decréscimo de pressão.

Poucos trabalhos [22-25] têm sido realizados com $\mathrm{SFE}$ diretamente em matrizes aquosas, apesar de existirem células extratoras próprias para este uso [7]. Este tipo de extração tem maiores possibilidades quando o analito apresenta solubilidade reduzida em água ou é volátil [26].

A SFE pode ser aplicada diretamente às matrizes aquosas de duas maneiras: a) colocando a amostra diretamente na célula de extração especial ou b) adicionando a amostra a um suporte sólido (o mais usado é Celite), que é colocado na célula de extração. A segunda maneira apresenta a vantagem de se utilizar o mesmo equipamento usado para amostras sólidas e a desvantagem de permitir a extração de um volume reduzido de amostra [26].

Aalternativafreqüentementeutilizada,emsubstituição a SFE direta, para extração de matrizes líquidas, é o uso da SPE previamente à SFE. Primeiramente, a amostra aquosa é submetida à SPE, utilizando como sorvente disco de extração com grupos octadecil (C18) ou outro, e posteriormente a fase sólida, contendo os solutos de interesse, é levada para a SFE [26]. Isto, pode acarretar perdas de reprodutibilidade, aumento do erro da análise e diminuição da recuperação, pois ocorre o acoplamento e a soma de duas técnicas de extração, cada qual com suas desvantagens. Além disso, a extração dos analitos retidos em fase sólida utilizando eluição com solvente é mais simples e rápida que a eluição usando SFE, o que envolveria, ainda, o desenvolvimento de um novo método. A vantagem do uso do SF para extrair os analitos da fase sólida, estaria centralizada, principalmente, em aplicações envolvendo o uso "on-line" de cromatografia gasosa (GC) pois, como a maioria dos SF é um gás em temperatura ambiente, isto facilitaria o acoplamento. Porém, a SFE com matrizes aquosas direta apresenta a desvantagem de necessitar de extrações contínuas (em recirculação) para melhorar as recuperações, que mesmo assim são menores que as obtidas com SPE/SFE. Desta forma, a SFE direta torna-se mais demorada.

Os contaminantes mais estudados em água são os $\mathrm{PAH}$, fenóis e pesticidas.
Messer e Taylor [27] estudaram a recuperação de traços de 39 analitos semi-voláteis de amostras de água fortificadas. Neste estudo foi utilizado 1 litro de amostra, que primeiramente foi passado por um disco de extração, Empore C18, sendo posteriormente extraído em sistema de SFE.

Foi realizada uma SFE com dióxido de carbono puro e outra com dióxido de carbono modificado com acetona (melhor condição para os compostos mais polares). Em ambos os casos, a coleta do analito foi feita em cartucho C18, sendo eluído posteriormente com diclorometano. A análise dos extratos foi feita por cromatografia gasosa acoplada ao espectrômetro de massas (GC/MS). As recuperações obtidas variaram entre $35-158 \%$, com estimativa do desvio padrão relativo entre $3,3-15 \%$.

Sandra et al. [28] analisaram amostras de suco de fruta fortificadas com pesticidas, utilizando SFE e GC/MS. Os autores verificaram que a adição de uma fase sólida na célula de extração foi essencial, e para este propósito foi usada a fase Chromsorb W, formando um "sandwich" com a amostra líquida. Após as extrações a coleta foi feita em cartucho C18 e as recuperações obtidas ficaram entre $85-103 \%$.

Kane et al. [29] compararam os resultados obtidos, para extração de surfactantes não-iônicos utilizando a SFE direta de amostras aquosas e o uso de SPE previamente à SFE. O método de SFE direta utilizou uma célula de extração modificada para maximizar a exposição do analito e a extração foi realizada continuamente até atingir $2 \mathrm{~h}$. As recuperações obtidas com SFE direta não excederam $60 \%$, com um tempo de extração de $2 \mathrm{~h}$, enquanto que com o uso de $\mathrm{SPE} / \mathrm{SFE}$ as recuperações foram de aproximadamente 90\% e o tempo de extração foi de $30 \mathrm{~min}$.

\section{c) Matrizes gasosas (ar)}

Muitos compostos orgânicos voláteis podem ser encontrados no ar (atmosférico, de ambiente fechado ou aberto), principalmente sorvidos em material particulado, poeira ou aerossóis, apontando possíveis contaminações ambientais. Como se trata de materiais que estariam entrando diretamente em nossas vias respiratórias, sua análise é de grande interesse.

Vários processos antropogênicos e biogênicos contribuem para a presença de compostos orgânicos na fase particulada da troposfera, entre eles: a emissão 
de veículos movidos à gasolina e diesel, a queima de madeira, a abrasão de superfícies de folhas de plantas, o cozimento de alimentos, o uso de equipamentos movidos a gás natural, a fumaça de cigarros, etc.. Cada uma destas fontes emite uma mistura complexa de compostos orgânicos e como conseqüência, os aerossóis ambientais contêm mais de cem compostos. Algumas das classes de compostos geralmente encontradas são: os alcanos, os ácidos carboxílicos, os PAH, os monoterpenes, os furanos, os fenóis, os benzenos alquilados e até os pesticidas [30].

Para análise desta matriz, com interesse nos contaminantes orgânicos voláteis livres ou sorvidos no material particulado, a primeira etapa é a passagem do ar por um filtro para retenção dos analitos e este filtro é submetido à extração ou o material sólido nele retido. Este procedimento é inerente à matriz e portanto não constitui um fator complicante na SFE, que ainda apresenta a vantagem de que, na maioria dos casos, a mesma célula utilizada para coleta da amostra também é usada na extração desta, diminuindo a manipulação e portanto os erros.

Swami et al. [31] retiveram os termicidas, clordane e clorpirifos, provenientes do ar ambiente, em Florisil e os submeteram a SFE com dióxido de carbono como $\mathrm{SF}$, em temperatura de $80^{\circ} \mathrm{C}$ e pressão de $37,9 \mathrm{MPa}$. O material extraído foi coletado em cartucho de fase sólida (Bondasil C18) e eluído com hexano (uma porção de $1,3 \mathrm{~mL}$ e outra de $1 \mathrm{~mL}$ ). A técnica de análise utilizada foi GC com detector de captura de elétrons. As eficiências de retenção dos analitos em Florisil e as eficiências de extração foram, em média, de $85 \%$. Utilizando $20 \mathrm{~m}^{3}$ de ar eles obtiveram limites de detecção de $0,1 \mathrm{ng} / \mathrm{m}^{3}$ para clordane e $1 \mathrm{ng} / \mathrm{m}^{3}$ para clorpirifos.

Para avaliar a qualidade dos resultados obtidos com a SFE muitos autores aconselham a comparação com resultados obtidos com outras técnicas empregadas com a mesma finalidade. Liompart et al. [32] apresentaram uma comparação entre as principais técnicas que vêm substituindo a tradicional extração Soxhlet: a SFE, a USE e a MAE. As três técnicas foram utilizadas para extração de compostos fenólicos (fenol, o-cresol, m-cresol e p-cresol) em solos, tendo os resultados de recuperação e precisão comparados. A Tabela 3 apresenta os principais parâmetros de extração de cada técnica.

A SFE foi realizada com dióxido de carbono e o modificador, metanol, foi adicionado diretamente na amostra. Para a coleta do extrato utilizou cartucho de fase sólida $\mathrm{C} 18$, com posterior eluição com hexano. Foram testadas extrações com SF e microondas com a amostra derivatizada com piridina.

Tabela 3. Parâmetros utilizados na extração de fenóis em solo por SFE, MAE e USE.

\begin{tabular}{|c|c|c|c|}
\hline Parâmetro & SFE & MAE & USE \\
\hline $\begin{array}{l}\text { Temperatura de } \\
\text { extração }\left({ }^{\circ} \mathrm{C}\right)\end{array}$ & 45 & 130 & Ambiente \\
\hline \multirow{2}{*}{$\begin{array}{l}\text { Volume de } \\
\text { solvente }(\mathrm{mL})\end{array}$} & 0,1 (metanol) & 2 (hexano) & \multirow{2}{*}{$\begin{array}{l}30 \\
\text { (diclorometano) }\end{array}$} \\
\hline & $\begin{array}{l}2 \text { (hexano, } \\
\text { eluição) }\end{array}$ & 8 (acetona) & \\
\hline $\begin{array}{l}\text { Tempo total de } \\
\text { extração (min) }\end{array}$ & 29,0 & 3,87 & 0,58 \\
\hline
\end{tabular}

A SFE foi realizada com dióxido de carbono e o modificador, metanol, foi adicionado diretamente na amostra. Para a coleta do extrato utilizou cartucho de fase sólida C18, com posterior eluição com hexano. Foram testadas extrações com SF e microondas com a amostra derivatizada com piridina.

Para amostras com maior conteúdo de carbono (maior retenção dos analitos), a SFE apresentou resultados de recuperação menores que a MAE. Nos demais casos, as recuperações das duas técnicas foram boas (próximas a 100\%) e quase 50\% superiores aos resultados obtidos com a USE.

Sabendo dos resultados (recuperações com SFE equivalentes as obtidas com MAE, sendo ambas superiores as obtidas com USE), pode-se observar novamente a Tabela 3 e verificar que a SFE apresentou maior tempo de preparo da amostra (25 min), mas menor consumo de solvente orgânico $(0,1 \mathrm{~mL}$ de metanol), além de uma temperatura bem menor que a utilizada na MAE. Porém, deve-se lembrar que o custo de implementação da SFE é maior que da MAE e que os autores realizaram de 4-6 extrações simultâneas no sistema de MAE (o qual permite até 12 extrações simultâneas), enquanto que a SFE não permite extrações simultâneas.

Heemken et al. [19] compararam o uso de SFE e ASE com extração Soxhlet, USE e saponificação metanólica para determinação de microcontaminantes orgânicos em material marinho particulado. Os analitos estudados incluíram $\mathrm{PAH}$, hidrocarbonetos alifáticos e clorados e os sedimentos marinhos analisados foram materiais certificados.

As recuperações obtidas, para os $\mathrm{PAH}$, com SFE 
variaram entre 96 e 105\% e com ASE entre 97 e $108 \%$. Comparando com os valores certificados, as recuperações de SFE e ASE ficaram entre 86 e 88 \% destes valores.

Os resultados de recuperação obtidos para os alcanos, utilizando SFE, de 93 à 115\%, e ASE, de 94 à 107\%, foram iguais aos obtidos com Soxhlet, USE e MAE. As estimativas de desvio padrão relativos estavam na faixa de 2,9 à 7,5 \% para $\mathrm{PAH}$ e alcanos, usando SFE e ASE.

A vantagem da extração com saponificação metanólica é que a quantidade de água da matriz não influencia na extração, porém o tempo de análise de $2,5 \mathrm{~h}$ e o volume de solvente orgânico, de $100 \mathrm{~mL}$ (hexano), são grandes desvantagens.

A maior vantagem de ASE foi o tempo de extração (15 min), contra 90 min da SFE. A vantagem da SFE foi o menor consumo de solvente $(15 \mathrm{~mL})$ contra 20 $\mathrm{mL}$ da ASE, porém a diferença é pequena.

Bowyer e Plei1 [33] utilizaram a extração Soxhlet para comparar os resultados obtidos com SFE na extração de compostos orgânicos de amostras de carpetes. Em ambas as técnicas de extração, as amostras de carpete foram extraídas diretamente, sem tratamento prévio. $\mathrm{Na}$ extração Soxhlet foram utilizados $200 \mathrm{~mL}$ de diclorometano e refluxo por 16 à 18 horas. Na SFE foi utilizado dióxido de carbono como $\mathrm{SF}$ e a coleta foi realizada em 3 à $4 \mathrm{~mL}$ de diclorometano, com um tempo total de extração entre 70 e 80 minutos.

As extrações Soxhlet e SFE forneceram resultados similares, em número e tipos de compostos extraídos. Isto pode ser visto na Figura 4, que mostra uma comparação entre os cromatogramas obtidos por GC/MS, para os extratos das duas técnicas.

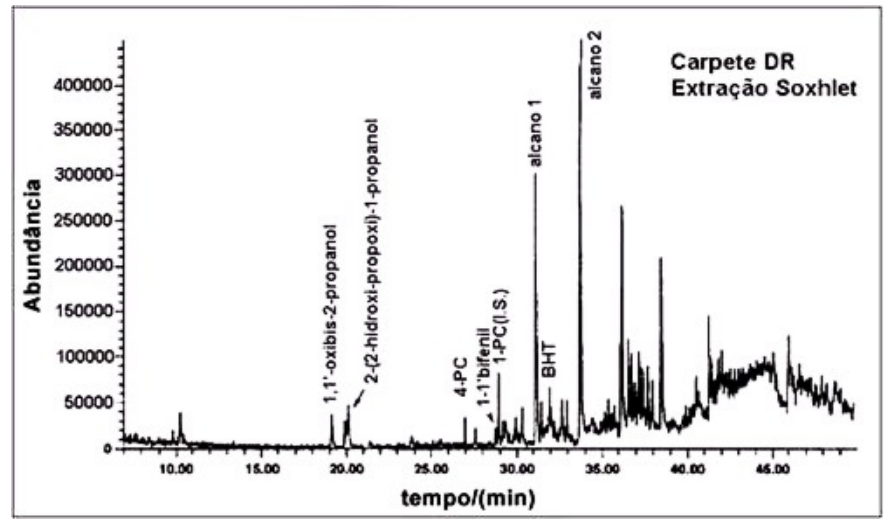

Figura 4a. Cromatograma de íons totais ilustrando os resultados obtidos para a extração Soxhlet de uma amostra de carpete.

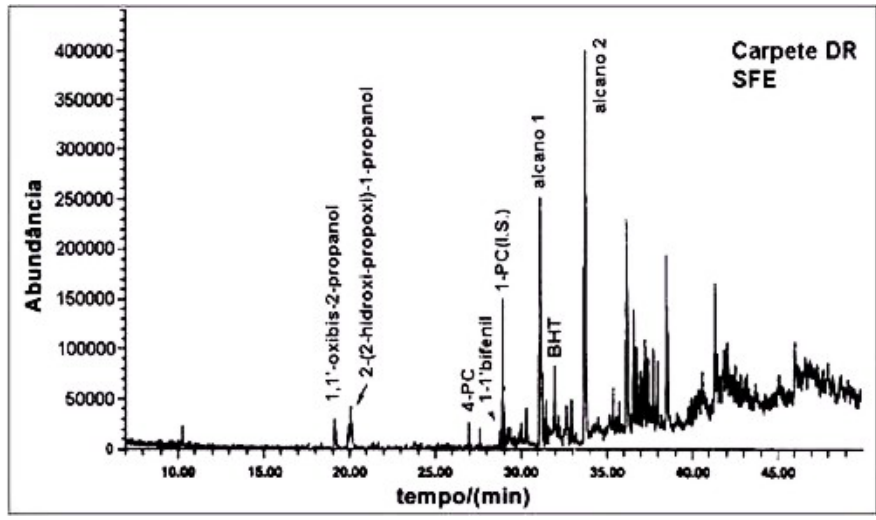

Figura 4b. Cromatograma de íons totais ilustrando os resultados obtidos para a extração SFE de uma amostra de carpete.

Devido às vantagens que a $\mathrm{SFE}$ apresenta em relação à extração Soxhlet, principalmente em termos de tempo de extração e consumo de solventes, ela foi considerada uma alternativa viável e superior, no caso apresentado.

\section{Drogas de abuso}

Uma das aplicações neste campo refere-se à análise de cabelo humano para verificação da presença de cocaína e benzolegonina [34].

Radcliffe et al. [35] apresentaram um breve relato das atividades desenvolvidas com auxílio de fluído supercrítico na determinação de drogas derivadas do ópio, cocaína, cannabis e sedativos. As metodologias utilizadas podem servir tanto para determinar a concentração destas drogas no momento da morte quanto para avaliar a dependência a longo prazo. Também foram apresentados resultados das análises de impressões digitais e resíduos de explosivos.

\section{Alimentos}

Determinação de flavorizantes em framboezas [36] e determinação de pesticidas em frutas e vegetais [37].

Boselli e Caboni [38] realizaram a extração, em microescala, de fosfolipídeos em amostras de ovo em pó, utilizando dióxido de carbono supercrítico em uma densidade de $1,06 \mathrm{~g} / \mathrm{mL}$ (pressão de 51,7 MPa e temperatura de $40{ }^{\circ} \mathrm{C}$ ), em uma proporção de $67 \mathrm{~g}$ de extrato por $100 \mathrm{~g}$ de amostra. Os resultados mostram que a metodologia proposta é uma boa alternativa para fins analíticos.

Mohamed et al. [39] realizaram a extração de colesterol 
em manteiga com metano supercrítico obtido em temperaturas de 40,55 e $70{ }^{\circ} \mathrm{C}$ e pressões na faixa de 8,5 a 24,1 MPa, em fluxo semi contínuo. Para determinar a seletividade do processo, a operação de extração foi seguida de adsorção em alumina. Com a metodologia proposta foi possível reduzir o nível de colesterol para 3\% do valor inicial.

\section{Referências Bibliográficas}

1. Taylor, L.T., "Supercritical Fluid Extraction", John Wiley \& Sons, INC., New York, 1996, p 181.

2. Skoog, D.A.; Leary, J.J., "Principles of Instrumental Analysis", 4th ed., Saunders College Publishing, Philadelphia, 1995, p. 670-671.

3. Zougagh, M.; Valcárel, M. Rios, A., "Supercritical fluid extraction: a critical review of its analytical usefulness", Trends in Analytical Chemistry, 2004, 23: 399 .

4. Socantaype, F.V. H., Dissertação de Mestrado: "Remoção de colesterol e Fracionamento do Óleo de Manteiga com Etano Supercrítico", Universidade Estadual de Campinas, Faculdade de Engenharia Química, Campinas, SP, 1996, p. 2,3, 7-17.

5. Camel, V., "Supercritical Fluid Extraction as a Useful Method for Pesticides Determination”, Analusis Magazine, 1998, 26: M99.

6. Stuart, I.A.; MacLachlan, J.; McNaughtan, A., "Compounds of Agricultural Significance Using Environmental Analytical Supercritical Fluid Extraction”, Analyst, 121 (1996) 11R.

7. Chaudot,X.;Tambuté,A.; Caude,M., "L'Extraction en Phase Supercrtitique: Un Nouvel Outil Analytique Performant Pour le Traitement de L'échantillon”, Analusis, 1996, 25: 81.

8. Dean, J.R., "Extraction of Polycyclic Aromatic Hydrocarbons from Environmental Matrices: Practical Considerations for Supercritical Fluid Extraction", Analyst, 1996, 121: 85R.

9. Benner Jr, B.A., "Summarizing the Effectiveness of Supercritical Fluid Extraction of Polycyclic Aromatic Hydrocarbons from Natural Matrix Environmental",
Anal. Chem., 1998, 70: 4594.

10. Berset, J.D.; Holzer, R., "Quantitative Determination of Polyciclic Aromatic Hydrocarbons , Polychlorinated Biphenyls and Organochlorine Pesticides in Sewage Sludges Using Supercritical Extraction and Mass Spectrometric Detection”, J. Chromatogr. A, 1999, 852: 545.

11. Vérillon, F., "Supercritical Fluids Highlighted at Pittcon'97”, Analusis, 1997, 25: M21.

12. Vérillon, F., "Supercritical or Not, Pressurized fluids at Pittcon'98”, Analusis, 1998, 26: M81.

13. Field, J.A.; Monochan, K.; Reed, R., "Coupling Supercritical CO2 and Subcritical (Hot) Water for the Determination of Dacthal and Its Acid Metabolites in Soil”, Anal. Chem., 1998, 70: 1956.

14. Crescenzi, C.; D'Ascenzo, G.; Di Corcia, A.; Nazzari, M.; Marchese, S.; Samperi, R., "Multiresidue Herbicide Analysis in Soil: Subcritical Water Extraction With an Online Sorbent Trap", Anal. Chem., 1999, 71: 2157.

15. Chester, T.L.; Pinkston, J.D.; Raynie, D.E., "SupercriticalFluid Chromatography and Extraction", Anal. Chem., 1998, 70: 301R.

16. http://www.pnl.gov/WEBTECH/voc/sfe.html (acessado em 24/02/2000).

17. McNally, M.E.P., "Advances in Environmental SFE", Anal. Chem., 1995, 67: 308A.

18. Pichon, V., "Traitment de L'échantillon Environnemental: Évolution et Perspectives", Analusis, 1997, 25: 101.

19. Heemken, O.P.; Theobald, N.; Wenclawiak, B.W., "Comparison of ASE and SFE With Soxhlet, Sonification, and Methanolic Saponification Extractions for the determination of Organic Micropollutants for the Determination of Organic Micropollutants in Marine Particulate Matter", Anal. Chem., 1997, 69: 2171.

20. Morselli, L.; Setti, L.; Iannuccilli, A.; Maly, S.; Dinelli, G.; Quattroni, G., "Supercritical Fluid Extraction for the Determination of Petroleum 
Hydrocarbons in Soil", J. Chromatogr. A, 1999, 845: 357.

21. Rissato,S.R.;Galhiane,M.S.;Apon,B.M.;Arrusa, M.S.P., "Multiresidue analysis of pesticides in soil by supercritical fluid extraction/gas chromatography with electron-capture detection and confirmation by gas chromatography-mass spectrometry", J. Agric. Food Chem., 2005, 53: 62.

22. Hedrick, J.L.; Taylor, L.T., "Supercritical Fluid Extraction Strategies of Aqueous Based Matrices”, J. High Resolut. Chromatogr., 1990, 13: 312.

23. Barnabas, I.J.; Dean, J.R.; Hitchen, S.M.; Owen, S.P., "Supercritical Fluid Extraction of Organochlorine Pesticides From an Aqueous Matrix", J. Chromatrogr. A , 1994, 665: 307.

24. Grasso, P.; Benfenati, E.; Terreni, M.; Pregnolato, M.; Natangelo, M.; Pagani, G., "Deuterated Internal Standards for Gas Chromatographic-mass Spectrometric Analysis of Polar Organophosphorus Pesticides in Water Samples", J. Chromatogr. A, 1998, 822: 91.

25. Simons, B.R.; Stewart, J.T., "Supercritical Fluid Extraction of Selected Pharmaceuticals From Water and Serum”, J. Chromatogr. B, 1997, 688: 291.

26. Janda, V.; Mikesová, M.; Vejrosta, J., "Direct Supercritical Fluid Extraction of Water-based Matrices”, J. Chromatogr. A, 1996, 733: 35.

27. Messer, D.C.; Taylor, L.T., "Recovery of Trace Semivolatile Analytes from Reagent Water Using Solid-Phase deposition and Supercritical Fluid Elution”, LC-GC, 1996, 14: 134.

28. Sandra, P.; Kot, A.; Medvedovici, A.; David, F., "Selected Applications of the Use of Supercritical Fluids in Coupled Systems”, J. Chromatogr. A, 1995, 703: 467.

29. Kane, M.; Dean, J.R.; Hitchen, S.M., "Extraction of Surfactants from Aqueous Media by Supercritical Fluid Extraction", Analyst, 1995, 120: 355.

30. Hansen, K.J.; Hansen, B.N.; Cravens, E.; Sievers, R.E., "Supercritical Fluid Extraction-Gas Chromatographic Analysis of Organic Compounds in Atmospheric Aerosols", Anal. Chem., 1995, 67: 3541.

31. Swami, K.; Narang, A.S.; Narang, R.S., "Determination of Chlordane and Chlopyrifos in Ambient Air at Low Nanogram-Per-Cubic Meter Levels by Supercritical Fluid Extraction", J. Assoc. Off Anal. Chem. Inter., 1997, 80: 74.

32. Liompart, M.P.; Lorenzo, R.A.; Cela, R.; Li, K.; Bélanger, J.M.R.; Paré, J.R.J., "Evaluation of Supercritical Fluid Extraction, Microwave-assisted Extraction and Sonification in the Determination of some Phenolic Compounds From Various Soil Matrices”, J. Chromatogr. A, 1997, 774: 243.

33. Bowyer, J.R.; Pleil, J.D., "Comparison of Supercritical Fluid Extraction and Soxhlet Extraction of Organic Compounds from Carpet Samples", J. Chromatogr. A, 1997, 787: 171.

34. Morrison, F.J.; Cheseer, N.S.; Yoo, J.W.; Selavka, M., "Matrix and Modifier Effects in the Supercritical Fluid Extraction of Cocaine and Benzoylecgonine from Human Hair”, Anal. Chem., 1998, 70: 163.

35. Radcliffe, C.; Maguire, K.; Lockwood, B., "Applications of Supercritical Fluid Extraction and Chromatography in Forensic Science”, J. Biochem. Biophys. Methods, 2000, 43: 261.

36. Ibanez, E.; Lopez-Sebastian, S.; Ramos, E.; Tabera, J.; Regero, G., "Analysis of Highly Volatile Components of Foods by Off-Line SFE/GC", J. Agric. Food Chem., 1997, 45: 3940.

37. Lehotary, S.J., "Supercritical Fluid Extraction of Pesticides in Foods", J. Chromatogr. A, 1997, 785: 289.

38. Boselli, E.; Caboni, M.F., "Supercritical Carbon Dioxide Extraction of Phospholipids From Dried Egg Yolk Without Organic Modifier", J. Supercrit. Fluids, 2000, 19: 45.

39. Mohamed, R.S.; Saldan, M.D.A.; Socantaype F.H.; Kieckbusch, T.G., "Reduction in the Cholesterol Content of Butter Oil Using Supercritical Ethane Extraction and Adsorption on Alumina", J. Supercrit. Fluids, 2000, 16: 225. 